\title{
Electrocatalytic Activity and Stability of M-Fe Catalysts Synthesized by Polymer Complex Method for PEFC Cathode
}

\author{
Yiwei Ou, ${ }^{\text {a }}$ Hiromu Kumagai, ${ }^{a}$ Fengxiang Yin, ${ }^{\text {a }}$ Saori Okada, ${ }^{\text {b }}$ Haruna Hatasawa, ${ }^{b}$ \\ Hiroyuki Morioka, ${ }^{b}$ Kazuhiro Takanabe, ${ }^{c, *}$ Jun Kubota, ${ }^{a}$ and Kazunari Domen ${ }^{\text {a,z }}$ \\ ${ }^{a}$ Department of Chemical System Engineering, The University of Tokyo, Tokyo 300-1514, Japan \\ ${ }^{b}$ Toppan Technical Research Institute, Toppan Printing Co., Ltd., Saitama, 345-8508, Japan \\ ${ }^{c}$ KAUST Catalysis Center, King Abdullah University of Science and Technology, 23955-6900, Saudi Arabia
}

\begin{abstract}
The polymerized complex (PC) method was used to synthesize highly dispersed iron-based catalysts for the oxygen reduction reaction (ORR). The catalysts were prepared with an addition of 1,10-phenanthroline (Phen) and transition metals (M), such as Ta, Ti, and $\mathrm{W}$, in an attempt to enhance the ORR activity and durability of the catalysts. The composition and properties of the catalysts were characterized by thermogravimetric analysis, X-ray diffraction, and X-ray photoelectron spectroscopy. The catalyst components, after extensive dissolution in a strong acid solution, were characterized by inductively coupled plasma mass spectroscopy and ultraviolet-visible spectroscopy. It was found that the Ti-Fe catalyst showed improved ORR performance, and the Ta-Fe catalyst showed enhanced stability towards ORR in acidic solution. The catalytic activity and stability for ORR was observed by adding Ti or Ta into the catalyst formulation, suggesting that the interaction between added hetero-ions ( $\mathrm{Ti}$ and $\mathrm{Ta}$ ) and ionic Fe active sites was beneficial for the ORR. A single-cell test with the synthesized catalyst in the cathode initially generated a high power density, but the low stability remains an issue to be solved.
\end{abstract}

(C) 2011 The Electrochemical Society. [DOI: 10.1149/2.034112jes] All rights reserved.

Manuscript submitted July 29, 2011; revised manuscript received September 1, 2011. Published November 1, 2011.

Polymer electrolyte fuel cells (PEFCs) have long been considered among the most promising devices for next-generation power sources for electric vehicles because of their high energy conversion efficiency and zero $\mathrm{CO}_{2}$ emission. ${ }^{1}$ The dominant reaction at the PEFC cathode is the oxygen reduction reaction (ORR), and the overpotential of the ORR mainly determines the overall efficiency of PEFCs. Carbonsupported platinum catalysts are widely used for the cathode, which leads to the high cost of PEFCs developed to date. The dissolution of Pt is another issue to be overcome at the cathodes, where a highly acidic environment and a positive potential are prevalent. ${ }^{2}$ Therefore, the development of abundant, highly active, and stable non-noble metal cathodes has drawn extensive attention in the relevant research fields. ${ }^{3}$

In the past decades, many non-noble metal catalysts based on metal ions (typically Fe- and Co- based) bound to nitrogen have been studied, and $\mathrm{Co}-\mathrm{N}_{4}$ macrocycles were observed to catalyze the ORR as early as the 1960s. ${ }^{4}$ Many recent efforts have investigated Fe containing macrocyclic compounds such as meso-tetraphenylporphyrin iron chloride (ClFeTPP), ${ }^{5}$ Co-Fe tetramethoxyphenylporphyrin (ClFeTMPP), ${ }^{6-8}$ iron perylene-3,4,9,10-tetracarboxylic-3,4,9, 10-dianhydride (PTCDA), ${ }^{9}$ and Fe 2,3,5-tripheynyltetrazol-2-ium chloride (TPTZ). ${ }^{10}$ Furthermore, extended optimization of synthetic parameters such as the reaction conditions (e.g., gases present, temperature) for heat treatment ${ }^{11,12}$ and optimum Fe loading in catalysts have been carried out. ${ }^{13,14}$ As a nitrogen-bearing organic compound, 1,10-phenanthroline (Phen) can form a stable complex with $\mathrm{Fe}^{2+}$, and $\mathrm{Fe}-\mathrm{N}_{\mathrm{x}}$ species derived from an $\mathrm{Fe}^{2+}$-phen complex could also serve as highly active sites for ORR. ${ }^{13,15,16}$ Dodelet's group proposed that pyridinic-type nitrogen in the structure of a phenanthroline can coordinate with the $\mathrm{Fe}$ ion in a catalytic active site, and N-bearing functionalities can bind cations to the micropores on carbon black (CB) particles. ${ }^{12,14} \mathrm{~A}$ catalytic site consisting of an iron cation coordinated by four pyridinic functionalities can provide a high ORR activity, comparable to that of platinum, but the stability remains unsatisfactory because of the disappearance ${ }^{17}$ or degradation ${ }^{18}$ of catalytic sites in harsh acidic and/or oxidizing conditions.

Some transition metal compounds in groups IV, V, and VI have been reported to show moderate ORR activity. Oxides like $\mathrm{TiO}_{\mathrm{x}}{ }^{19}$ and $\mathrm{NbO}_{\mathrm{x}}{ }^{20}$, and metal carbides like $\mathrm{WC}^{21}$ were found to exhibit ORR activity. Oxynitrides like $\mathrm{TaO}_{\mathrm{x}} \mathrm{N}_{\mathrm{y}}{ }^{22}$ and $\mathrm{ZrO}_{\mathrm{x}} \mathrm{N}_{\mathrm{y}}{ }^{23}$ were reported to reduce oxygen with even higher onset potentials than their oxide

\footnotetext{
* Electrochemical Society Active Member.

${ }^{\mathrm{z}}$ E-mail: domen@chemsys.t.u-tokyo.ac.jp
}

forms. Our previous paper reported that the polymerization complex (PC) method followed by treatment in flowing ammonia generated highly dispersed niobium-based catalytic sites on CB. ${ }^{24}$ Furthermore, the proper combination of different transition metals was found to either enhance ORR catalytic activity or improve catalytic stability, such as Ta-added WC, ${ }^{25} \mathrm{Ba}-\mathrm{Zr}-\mathrm{Nb}-\mathrm{O}-\mathrm{N} / \mathrm{CB}^{26}$, and $\mathrm{Co}-\mathrm{Ti}-\mathrm{O}-\mathrm{N} / \mathrm{CB}^{27}$

The $\mathrm{PC}$ method reported previously utilized highly dispersed metal ions in a polymer matrix and $\mathrm{CB}$, and these polymers were carburized and utilized as a catalyst component to ensure contact between metal ions and $\mathrm{CB} .{ }^{24,26}$ Our previous communication described how the addition of hetero-elements such as Ti reduces the dissolution of Co metal in acidic solution. ${ }^{27}$ In this work, we attempted to combine Phen-added $\mathrm{Fe}$ with three transition metals, $\mathrm{Ta}, \mathrm{Ti}$, and $\mathrm{W}$, to produce CB-supported M-Fe-N electrocatalysts using a PC method and subsequent $\mathrm{NH}_{3}$ treatment, and to examine the electrocatalytic activity and stability of the catalysts in acidic media and in a single-cell test.

\section{Experimental}

Catalyst preparation.- M-Fe-N/CB (M: None, Ta, Ti, W) catalysts were prepared by the PC method, as described in our previous paper. ${ }^{26,27}$ The required amount of $\mathrm{FeCl}_{3}$ (typically $\sim 0.98 \mathrm{~g}, 99.0 \%$, Wako Pure Chemical Industries: Wako) and $\mathrm{TaCl}_{5}$ (99.99\%, High $\mathrm{Pu}-$ rity Chemicals), $\mathrm{TiCl}_{4}\left(99.0 \%\right.$, Wako), or $\mathrm{WCl}_{6}(99.99 \%$, High Purity Chemicals) was dissolved in $100 \mathrm{~mL}$ of methanol with vigorous stirring. Then, citric acid (CA, 98.0\%, Wako), and ethylene glycol (EG, $99.5 \%$, Kanto Chemical) were added to the solution. The molar ratio of raw materials was adjusted to $\mathrm{M}: \mathrm{Fe}: \mathrm{CA}: \mathrm{EG}=1: 1: 10: 40$. The resulting mixture was concentrated and polymerized at $423 \mathrm{~K}$ until the mixture gelled. The required amount of CB $(\sim 5 \mathrm{~g}$, Vulcan XC-72R, Cabot Corp.), 1, 10-phenanthroline ( $\sim 2.5$ g, noted as Phen in this paper, Wako) and $150 \mathrm{~mL}$ of methanol were added to the gel, which was then heated to $473 \mathrm{~K}$ to obtain the precursor powder. After drying in a heating mantle for several hours, the precursor powder was placed in a tube furnace under an $\mathrm{NH}_{3}$ flow of $100 \mathrm{~mL} \mathrm{~min}{ }^{-1}$. The furnace temperature was increased at a ramping rate of $10 \mathrm{~K} \mathrm{~min}^{-1}$ and then kept at $1223 \mathrm{~K}$ for $5 \mathrm{~min}$.

Acid treatment.- To eliminate unstable metal species and evaluate the acid stability of the samples, $250 \mathrm{mg}$ of as-synthesized M-Fe-N/CB catalysts were immersed in $50 \mathrm{~mL}$ of $0.5 \mathrm{M} \mathrm{H}_{2} \mathrm{SO}_{4}$ solution for $24 \mathrm{~h}$ at $353 \mathrm{~K}$ under atmospheric conditions and then filtered. In order to elucidate the merits of the PC method and Phen addition, we also 
prepared an Fe-N/CB sample by the PC method without Phen and by a conventional impregnation method with Phen addition, using the procedures described in our previous work. ${ }^{27}$ The iron content was kept the same in the synthesis of all samples.

Physicochemical characterization.- The metal amounts in the catalyst samples before and after acid treatment were estimated by oxidizing the carbon species and monitoring the weight of the remaining components using thermogravimetric analysis (TGA; Rigaku Thermoplus TG8120), in which a scan rate of $10 \mathrm{~K} \mathrm{~min}^{-1}$ was applied from room temperature to $1273 \mathrm{~K}$ and the temperature was then kept

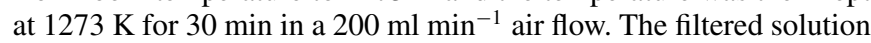
after acid treatment was collected and studied by inductively coupled plasma mass spectroscopy (ICP-MS; HP-450, Hewlett Packard) and ultraviolet-visible spectroscopy (UV-Vis; V-670, JASCO). The crystalline structures of the catalyst samples were analyzed using X-ray diffraction (XRD; RINT-Ultima III, Rigaku Corporation). The surface compositions and properties of the catalysts were analyzed by X-ray photoelectron spectroscopy (XPS; JPS-90SX, JEOL) using mg K $\alpha$ as the exciting radiation at a constant pass energy of $20 \mathrm{eV}$. The binding energy was referenced to the $\mathrm{Au} 4 \mathrm{f}_{7 / 2}$ peak at $83.8 \mathrm{eV}$ and the $\mathrm{C} 1 \mathrm{~s}$ peak of a carbon contaminant at $284.6 \mathrm{eV}$.

Electrochemical measurements.- The ORR currents were measured using a rotating disk electrode (RDE) with a geometric surface area of $0.636 \mathrm{~cm}^{2}$. The electrode was prepared as follows: $10 \mathrm{mg}$ of the catalyst sample after acid treatment, $350 \mu \mathrm{l}$ of ethanol, and $95 \mu \mathrm{l}$ of Nafion solution ( $5 \mathrm{wt}$ \%, Sigma-Aldrich) were mixed by ultrasonication for $30 \mathrm{~min}$ to form a catalyst ink. The electrode surface was polished with $0.05 \mu \mathrm{m}$ alumina slurry before coating with a catalyst suspension. A $28.3 \mu \mathrm{L}$ aliquot of the ink was dropped onto the clean disk electrode surface and then dried at room temperature in air to obtain a catalyst loading of $1 \mathrm{mg} \mathrm{cm}^{-2}$. The working electrode was mounted on a rotator (RRDE-3, BAS). A conventional threeelectrode single-vessel electrochemical cell was employed. A carbon rod and an $\mathrm{Ag} / \mathrm{AgCl}$ electrode were used as counter and reference electrodes, respectively. The $\mathrm{Ag} / \mathrm{AgCl}$ reference electrode was calibrated against the reversible hydrogen electrode (RHE) potential in $0.1 \mathrm{M}$ $\mathrm{H}_{2} \mathrm{SO}_{4}$, and all potentials in this article are indicated against RHE. The potential of the sample electrode was controlled by a potentiostat (HSV-100, Hokuto Denko). Before ORR measurements, the electrode was repeatedly polarized between $0.11-1.20 \mathrm{~V}_{\mathrm{RHE}}$ to achieve a stable cyclic voltammogram (CV) profile. The electrochemical activity for the ORR was determined from a linear sweep voltammogram (LSV) from 1.20 to $0.11 \mathrm{~V}_{\mathrm{RHE}}$ at a sweep rate of $5 \mathrm{mV} \mathrm{s}^{-1}$. The difference in currents between the $\mathrm{Ar}$ and $\mathrm{O}_{2}$ atmosphere reflected the proper ORR current. The current density was calibrated by the electrode geometric surface area and is indicated as $I_{\mathrm{ORR}}$ in this work.

Durability tests of the catalysts were carried out as follows: $44.5 \mu \mathrm{L}$ of the above catalyst ink was deposited on carbon paper (TGP-H-120, Toray) with a geometric area of $1 \mathrm{~cm}^{2}$ and then dried at room temperature in air to obtain a catalyst loading of $1 \mathrm{mg} \mathrm{cm}^{-2}$. The working electrode of carbon paper was first immersed in $0.1 \mathrm{M} \mathrm{H}_{2} \mathrm{SO}_{4}$, and the abovementioned ORR activity test was performed. Then, the electrode was repeatedly polarized between 0.11 and $1.12 \mathrm{~V}_{\mathrm{RHE}}$ at $50 \mathrm{mV} \mathrm{s}^{-1}$ for 100 cycles in Ar-purged solution. The solution was replaced, and the activity test was repeated. This procedure was repeated 10 times, so that the electrode underwent 1000 cycles of polarization. The ORR current in the activity test after each polarization treatment was recorded and analyzed.

Single-cell test. - A membrane-electrode-assembly (MEA) was prepared using (Ti-)Fe-N/CB and $\mathrm{Pt} / \mathrm{CB}$ for the cathode and anode catalysts, respectively. The (Ti-)Fe-N catalyst $\left(3.6 \mathrm{mg} \mathrm{cm}^{-2}\right)$ was loaded on a carbon sheet substrate (gas-diffusion layer) to a catalyst layer thickness of $\sim 35 \mu \mathrm{m}$. The ionomer to catalyst ratio was 0.6 . A Nafion 212 proton-membrane was employed, and the total electrode area of the MEA was $5 \mathrm{~cm}^{2}$. Pt/CB catalyst for the anode was obtained from Tanaka Kikinzoku Kogyo (TEC10E50E, 50 wt.\% Pt, 0.3 mg-
$\mathrm{Pt} \mathrm{cm} \mathrm{cm}^{-2}$ ). The temperature of the entire cell was maintained at $353 \mathrm{~K}$ and $\mathrm{H}_{2}$ (anode) and $\mathrm{O}_{2}$ (cathode) flows, humidified at $353 \mathrm{~K}$ under backpressures of 0 and $0.3 \mathrm{MPa}$ against atmosphere, were used at flow rates of $200-500 \mathrm{~cm}^{3} \mathrm{~min}^{-1}$.

\section{Results and Discussion}

Comparison of preparation methods. - It has been proposed in previous studies that the polymerization complex (PC) method is beneficial to the homogeneous dispersion of metal ions into a polymer network. ${ }^{28,29}$ High temperature treatment could carburize the polymer surrounding the metal ions and remove the undesired residual precursor material, ensuring good electronic contact between the catalytic active sites and the substrate. ${ }^{26}$ Furthermore, Dodelet's group reported that pyridinic-type nitrogen in Phen coordinated with Fe ions as the active sites for ORR, and the $\mathrm{N}_{4}$-metal structure could bond these active sties to the carbon support. . $^{2,14}$

Figure 1 compares the voltammograms of Fe-N/CB catalysts prepared by the PC method without Phen, with Phen impregnation, and those prepared by the PC method with Phen addition (PC-Phen method). All of the samples were treated in acid solution before the measurements, as indicated in experimental section. The ORR onset potentials (from $I_{\mathrm{ORR}}$ of $-1.5 \mu \mathrm{A} \mathrm{cm}^{-2}$ ) for the three catalysts were measured to be approximately $0.86,0.88$, and $0.90 \mathrm{~V}_{\mathrm{RHE}}$, respectively. The ORR current for the sample synthesized by the PC-Phen method was the highest, and was around $-1.30 \mathrm{~mA} \mathrm{~cm}-2$ at $0.6 \mathrm{~V}_{\mathrm{RHE}}$ at $1600 \mathrm{rpm}$. The PC-Phen sample, which took the merit of both polymerized complex method and 1,10-phenanthroline addition, gave the highest ORR current among all the catalyst samples. The PC method probably helped to further distribute the nitrogen-coordinated $\mathrm{Fe}$ ion functionalities over the carbon support, giving improved contact between catalytic sites and the substrate to obtain a catalytic activity close to the intrinsic activity of the catalyst. ${ }^{20}$ Moreover, the addition of Phen during the synthesis should ensure better Fe-N(-C) coordination than rough $\mathrm{NH}_{3}$ treatment at high temperatures, as demonstrated by the higher performance of the PC-Phen method than of the PC method without Phen addition.

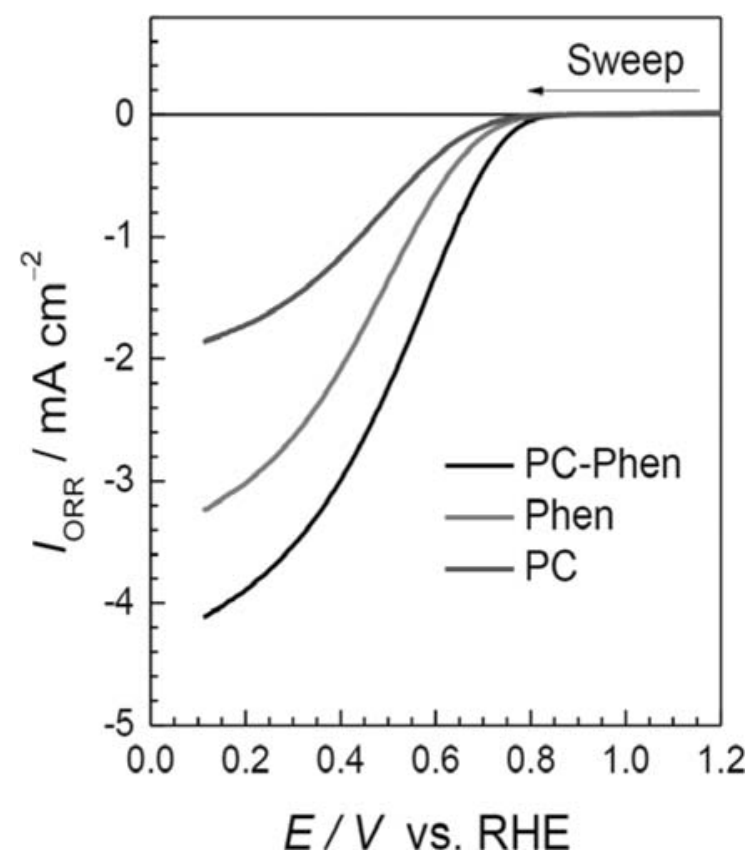

Figure 1. ORR voltammograms of $\mathrm{Fe}-\mathrm{N} / \mathrm{CB}$ catalysts prepared by three different methods, measured by RDE at $1600 \mathrm{rpm}$ in $0.1 \mathrm{M} \mathrm{H}_{2} \mathrm{SO}_{4}$ at $298 \mathrm{~K}$. Catalyst loading: $1.0 \mathrm{mg} \mathrm{cm}^{-2}$. $I_{\mathrm{ORR}}$ indicates the difference in current density between $\mathrm{O}_{2}$ and $\mathrm{Ar}$ atmospheres. The detailed preparation procedure can be found in the text. 
Table I. Amounts of residue remaining after oxidation at $1273 \mathrm{~K}$, measured by TGA, which corresponded to the estimated metal species ( $\mathrm{Fe}$ and the combined metal $\mathrm{M}$ ) content. Results for $\mathrm{Fe}$ N/CB, Ta-Fe-N/CB, Ti-Fe-N/CB, and W-Fe-N/CB before and after acid treatment are listed.

\begin{tabular}{lcccc} 
Catalyst & Fe-N/CB & Ta-Fe-N/CB & Ti-Fe-N/CB & W-Fe-N/CB \\
\hline $\begin{array}{l}\text { Before acid } \\
\text { treatment }\end{array}$ & $2.6 \%$ & $10.3 \%$ & $5.3 \%$ & $10.2 \%$ \\
$\begin{array}{l}\text { After acid } \\
\text { treatment }\end{array}$ & $0.4 \%$ & $8.9 \%$ & $2.9 \%$ & $7.8 \%$
\end{tabular}

Acid treatment.- TGA was used to estimate the remaining metal species content of the catalysts. Most $\mathrm{C}$ and $\mathrm{N}$ should have been gasified, while the metals remained in their oxidized form after extensive oxidation at $1273 \mathrm{~K}$ in air. As shown in Table I, four samples showed different remaining metal amount due to the different atomic mass of combined metal $(\mathrm{Ta}, \mathrm{Ti}, \mathrm{W})$. It is worth to note the Fe content of the Fe-N/CB sample before acid treatment was around $2.6 \mathrm{wt} . \%$, close to the optimum value for Fe-Phen catalyst for the ORR. ${ }^{13}$ As the molar amount of starting iron was the same for all M-Fe catalyst during the synthesis procedure, it can be supposed that Fe contents before acid treatment were around $2.6 \mathrm{wt} . \%$ for all samples reported in this work. After acid treatment at $353 \mathrm{~K}$, the Fe content in this sample dramatically decreased to about 0.4 wt. $\%$, indicating that most of the iron was dissolved during the acid treatment. Dissolution of the $\mathrm{Fe}$ probably also contributed to the mass loss in other M-Fe-N/CB samples. An ICP-MS test was used to quantify the dissolution degree of the combined metals. When 250-mg samples were immersed for $24 \mathrm{~h}$ in $0.5 \mathrm{M} \mathrm{H}_{2} \mathrm{SO}_{4}$ at $353 \mathrm{~K}, 99 \mathrm{mg}$ of tantalum $(0.55 \mathrm{mmol}), 628 \mathrm{mg}$ of titanium $(13.08 \mathrm{mmol})$ and $171 \mathrm{mg}$ of tungsten $(0.93 \mathrm{mmol})$ were dissolved for Ta-Fe, Ti-Fe, and W-Fe samples, respectively. It seems that the Ti species suffered from a low corrosion resistance in harsh acidic conditions. On the other hand, Ta and $\mathrm{W}$ showed a rather high tolerance to these acidic conditions.

UV-Vis spectroscopy was used to analyze the substances dissolved in the acid solution. In the spectra of all samples, a strong absorption was observed below $400 \mathrm{~nm}$, peaking around $304 \mathrm{~nm}$, which is characteristic of $\mathrm{Fe}_{2}\left(\mathrm{SO}_{4}\right)_{3}$ in $\mathrm{H}_{2} \mathrm{SO}_{4}$ aq. ${ }^{30}$ This should be the major form of Fe ions in $\mathrm{H}_{2} \mathrm{SO}_{4}$. However, the filtered acid solutions for $\mathrm{Fe}$ and $\mathrm{W}-\mathrm{Fe}$ samples were pale-red in color, while this color was hardly observed in the filtered solutions of Ti-Fe and Ta-Fe samples. The absorption spectra of the prepared $\left[\mathrm{Fe}(\text { phen })_{3}\right]^{2+}$ complex aq. solution and the

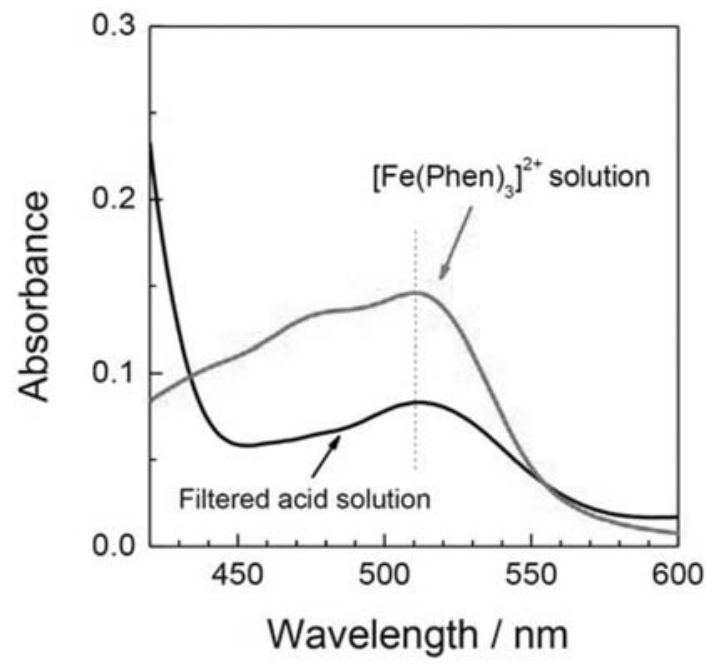

Figure 2. Visible absorption spectra of $\left[\mathrm{Fe}(\mathrm{phen})_{3}\right]^{2+}$ aqueous solution and dissolved substances in the filtered acid solution for the $\mathrm{Fe}-\mathrm{N} / \mathrm{CB}$ catalyst. $250 \mathrm{mg}$ of $\mathrm{Fe}-\mathrm{N} / \mathrm{CB}$ was immersed into $50 \mathrm{~mL}$ of $0.5 \mathrm{M} \mathrm{H}_{2} \mathrm{SO}_{4}$ solution for $24 \mathrm{~h}$ at $353 \mathrm{~K}$ dissolved substances from the Fe-N/CB catalyst in $0.5 \mathrm{M} \mathrm{H}_{2} \mathrm{SO}_{4}$ aq. are shown in Figure 2. The maximum wavelength in the visible region was $510 \mathrm{~nm}$ for $\left[\mathrm{Fe}(\text { phen })_{3}\right]^{2+}$ which gave an intense red color in aqueous solution. The absorption spectrum of the dissolved substances in $\mathrm{H}_{2} \mathrm{SO}_{4}$ aq. had a similar peak in the range of $450 \sim 600 \mathrm{~nm}$ and a maximum wavelength around $510 \mathrm{~nm}$. This result indicates that some of the $\mathrm{Fe}$ was dissolved in the acid solution as $\mathrm{Fe}^{2+}$-Phen or similar $\mathrm{N}$-coordinated complexes for $\mathrm{Fe}$ and $\mathrm{W}-\mathrm{Fe}$ samples, even after ammonia treatment at $1223 \mathrm{~K}$. The ICP-MS test also revealed the difference in dissolved amount of iron element. During the acid treatment, dissolved mass of iron were 5.3, 1.4, 4.0 and $4.8 \mathrm{mg} \mathrm{g}^{-1}$ for Fe, Ta-Fe, $\mathrm{Ti}-\mathrm{Fe}$, and $\mathrm{W}-\mathrm{Fe}$ samples, respectively. Extensive Fe dissolution as Fe-related complex in W-Fe sample indicates that $\mathrm{W}$ in the catalyst remains intact with $\mathrm{Fe}$ species in the $\mathrm{Fe}-\mathrm{N}-\mathrm{C}$ structure. On contrary, the low dissolution of $\mathrm{Fe}$ in the presence of $\mathrm{Ti}$ and $\mathrm{Ta}$ indicates an improved tolerance to the acid treatment. This is probably due to the interaction between hetero-element and $\mathrm{Fe}$ (or related functionality) that altered the chemical bonds to suppress dissolution of the Fe species.

$X R D$ and XPS.- The XRD patterns of catalyst samples are shown in Figure 3. Three major diffraction peaks were observed at $2 \theta=37.5,40.8$, and $42.9^{\circ}$ for all catalysts before acid treatment
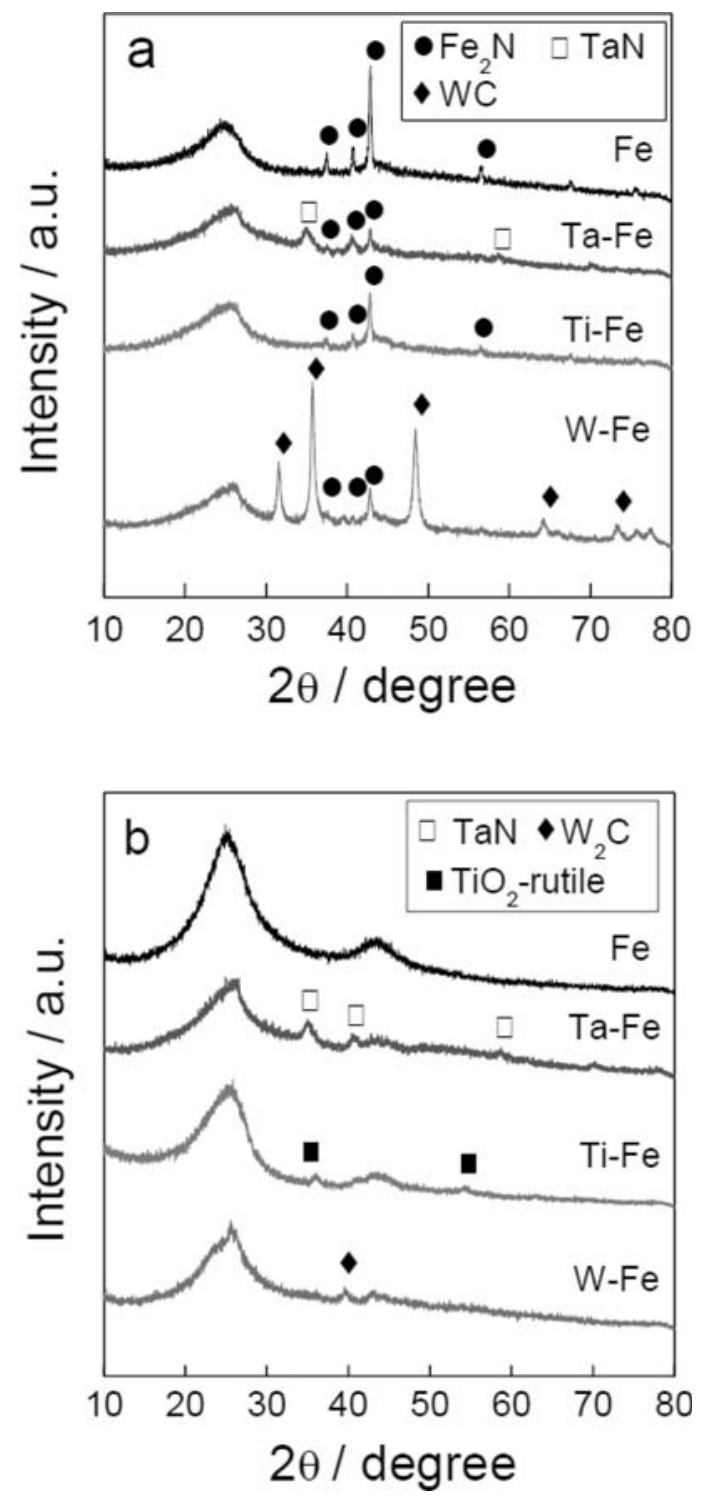

Figure 3. XRD patterns of prepared catalysts (a) before acid treatment and (b) after acid treatment. 
a
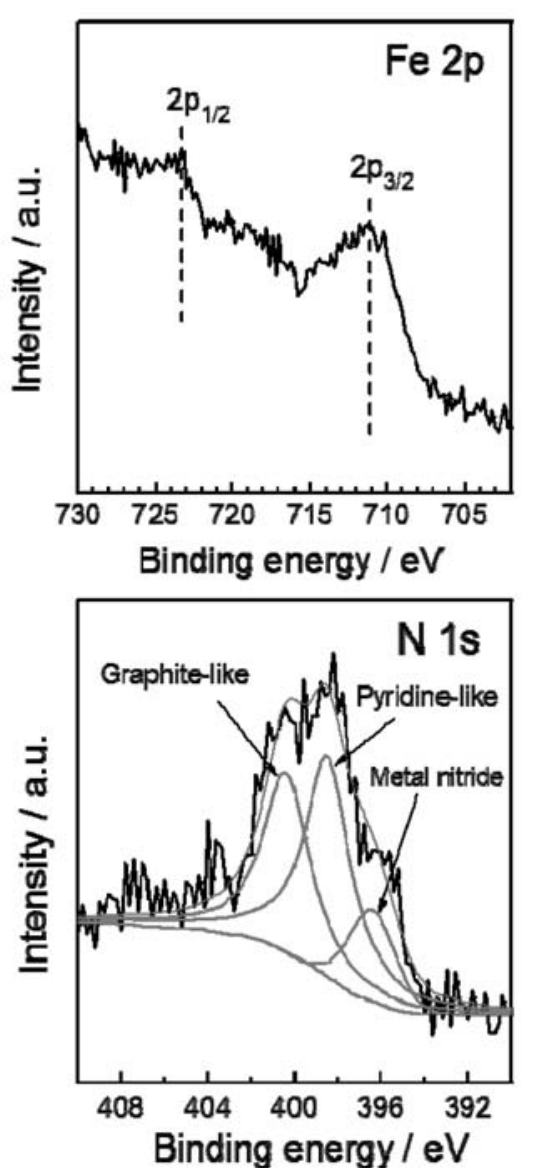

b
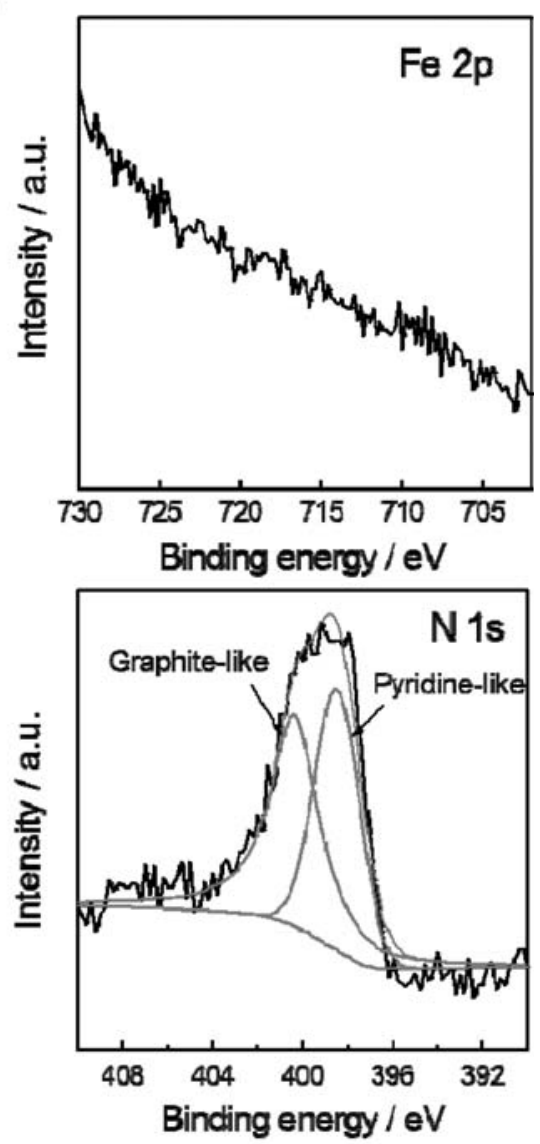

Figure 4. Fe $2 p$ and $N$ 1s XPS spectra of the FeN/CB catalyst (a) before acid treatment and (b) after acid treatment.
(Figure 3a), indicating the presence of an $\mathrm{Fe}_{2} \mathrm{~N}$ phase ${ }^{31}$ after nitridation of the precursor powders in $\mathrm{NH}_{3}$. It was reported that the interstitial $\zeta-\mathrm{Fe}_{2} \mathrm{~N}$ (orthorhombic) compound can be prepared by complete nitridation of iron in flowing ammonia at high temperatures. ${ }^{32}$ For the Ta-Fe-N/CB and W-Fe-N/CB catalysts, diffraction peaks due to TaN ${ }^{33}$ and $\mathrm{WC}^{34}$ could also be observed before acid treatment. No clear detection was made of $\mathrm{Ti}$ species in Ti-Fe-N/CB catalyst, showing that no Ti species existed as a crystalline phase in the sample. However, no Fe-related crystalline phases were detected for any of the catalysts after acid treatment (Figure $3 \mathrm{~b}$ ), and only a broad peak associated with the Vulcan XC-72R CB support at $2 \theta=25,43^{\circ}$ remained in the Fe-N/CB catalyst. ${ }^{26}$ After the acid treatment, the metallic $\mathrm{Fe}$ and nitrided Fe peaks disappeared, indicating that these iron species in their crystalline form were susceptible to dissolution in acidic media. Only a small amount of $\mathrm{Fe}$ and Phen formed a relatively stable ionic species for which no diffraction peak was detectable by XRD. For W-Fe-N/CB catalyst, the formerly sharp WC diffraction peaks completely disappeared after acid treatment. This indicates that the W-related crystalline phase is not stable in acidic conditions. It can be concluded that the addition of $\mathrm{W}$ into catalyst formulation did not inhibit dissolution of Fe species, most likely because of lack of the interaction between $\mathrm{Fe}$ and $\mathrm{W}$ species.

XPS analysis was used to further evaluate the surface composition and properties of the catalysts. The states of $\mathrm{Fe} 2 \mathrm{p}$ and $\mathrm{N} 1 \mathrm{~s}$ in $\mathrm{Fe}-\mathrm{N} / \mathrm{CB}$ before and after acid treatment are displayed in Fig. 4. Before the acid treatment, the binding energy of the $\mathrm{Fe} 2 \mathrm{p}_{3 / 2}$ peak was around 710.5 $711.2 \mathrm{eV}$, which was close to the reported iron state in various $\mathrm{Fe}_{\mathrm{x}} \mathrm{N}$ phases after high-temperature nitridation in ammonia. ${ }^{32,35}$ The $\mathrm{N} 1 \mathrm{~s}$ peak could be deconvoluted into three peaks. The peaks at $398.5 \mathrm{eV}$ and $400.4 \mathrm{eV}$ could be assigned to pyridine-like and graphite-like nitrogen atoms, respectively. ${ }^{36,37}$ The $\mathrm{N} 1 \mathrm{~s}$ peak at $396.5 \mathrm{eV}$ can be attributed to nitrogen atoms in the metal nitride, typically iron nitride. ${ }^{35}$
After acid treatment, the Fe $2 p$ spectrum showed only very weak and noisy signals, which resembled the Fe $2 p$ spectra of other M-Fe samples. This may have been due to the surface concentration for Fe being below the XPS detection limit. Accordingly, the N 1s deconvoluted peak at $396.5 \mathrm{eV}$ assigned to iron nitride also disappeared, demonstrating the complete dissolution of the iron nitride phase. It is worth mentioning that the peaks for N1s observed after acid treatment were similar to all the investigated catalysts with various heteroatoms. It is probable that the surface iron produced by the PC method was a highly dispersed ionic state. ${ }^{10}$

Figure 5 shows XPS narrow spectra for Ta 4f, Ti 2p, and W $4 \mathrm{f}$ after acid treatment on different M-Fe-N/CB catalysts. The Ta $4 \mathrm{f}_{7 / 2}$ peak had binding energies of 26.0 and $26.2 \mathrm{eV}$ before and after acid treatment, respectively. There was only a slight shift in binding energy, and both values were within the range of the binding energies of $\mathrm{Ta}^{5+}$ and $\mathrm{Ta}^{4+} .{ }^{38}$ It is worth noting that the Ta-Fe sample was fairly stable under acid treatment, as shown in the XRD and TGA results, and high oxidation state $\mathrm{Ta}^{5+}$ materials such as $\mathrm{Ta}_{3} \mathrm{~N}_{5}$ and $\mathrm{TaON}$ were reported to have excellent stability in acid solution. ${ }^{22}$ The binding energy of Ti $2 p_{3 / 2}$ shifted from $457.9 \mathrm{eV}$ before acid treatment to $459.0 \mathrm{eV}$ after acid treatment, and the latter binding energy is featured by $\mathrm{Ti}^{4+}$ in $\mathrm{TiO}_{2} .{ }^{19}$ It is possible that some of the titanium species was simply oxidized in the acid environment. The major $\mathrm{W} 4 \mathrm{f}_{7 / 2}$ peaks before and after acid treatment were 34.6 and $35.0 \mathrm{eV}$, respectively, which were close to the binding energy of $\mathrm{W}^{5+}$ in oxide form. ${ }^{39}$ In the $\mathrm{W} 4 \mathrm{f}$ spectra before acid treatment, there was an additional $4 \mathrm{f}$ peak at 31.4 $\mathrm{eV}$ for $7 / 2$ attributable to tungsten carbide, ${ }^{34}$ which was consistent with the XRD patterns that indicated a WC crystalline phase (Figure 3b). This peak completely disappeared after acid treatment. These XRD and XPS results indicate that Ta species remained relatively stable, whereas $\mathrm{Ti}$ and $\mathrm{W}$ species changed their chemical properties to some extent in the acid environment. 

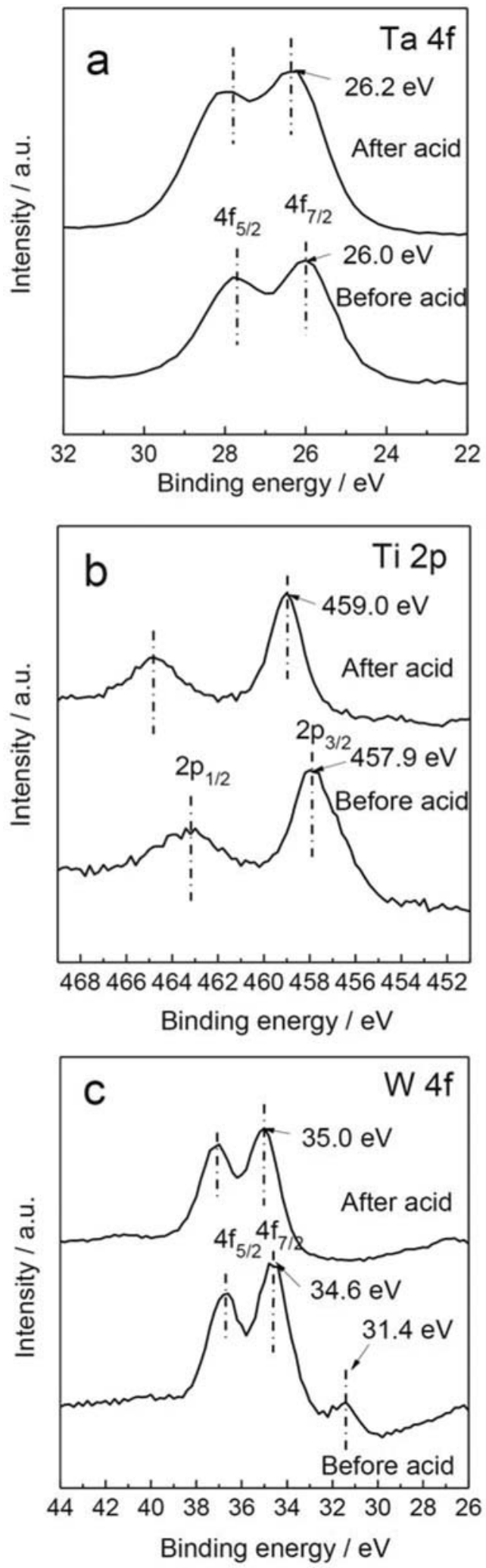

Figure 5. XPS spectra of (a) Ta 4f, (b) Ti 2p, and (c) W 4f, from different $\mathrm{M}-\mathrm{Fe}-\mathrm{N} / \mathrm{CB}$ (M: Ta, Ti or W) catalysts before and after acid treatment.

Electrocatalytic activity and stability for the ORR.- The ORR performance of four catalyst samples was examined by linear sweep voltammetry to a negative potential under an $\mathrm{Ar}$ and $\mathrm{O}_{2}$ atmosphere, and all ORR currents were taken at an RDE rotation speed of $1600 \mathrm{rpm}$.
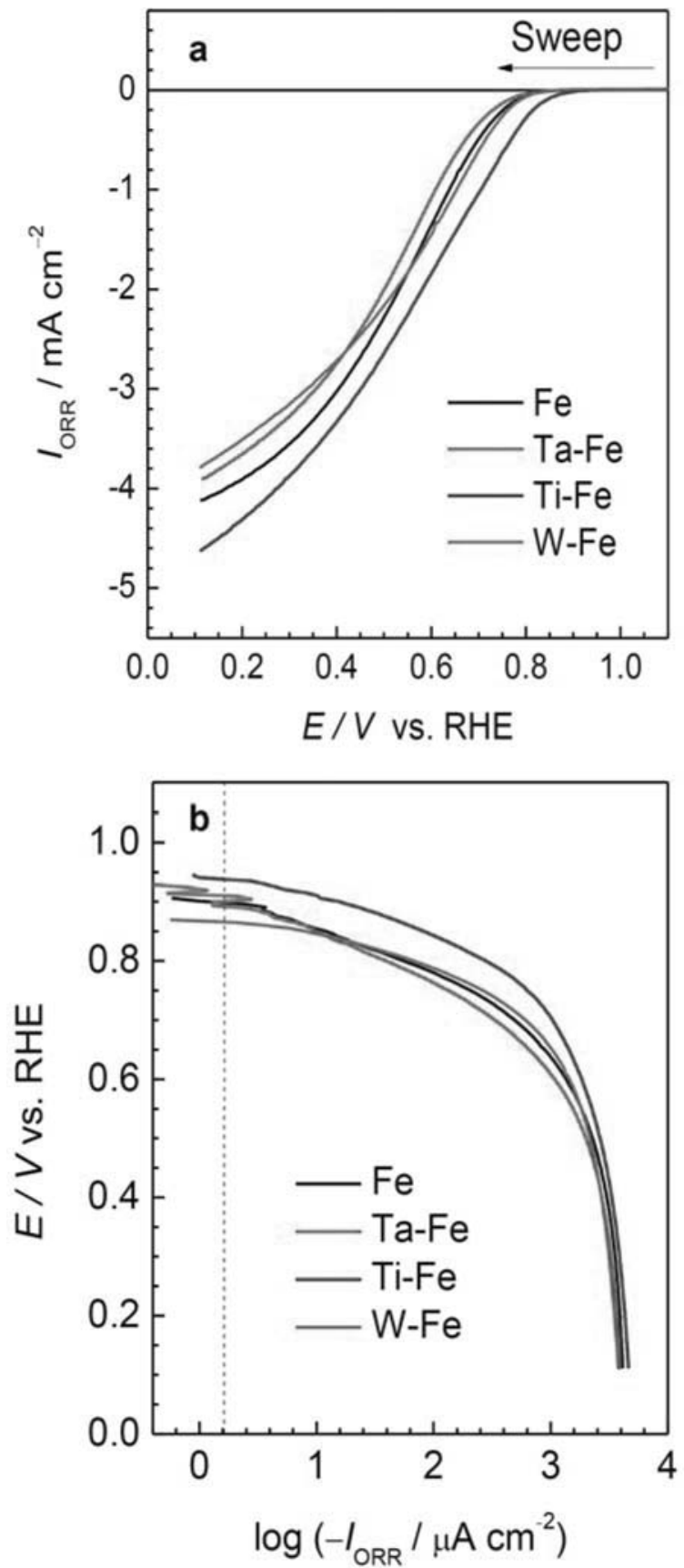

Figure 6. (a) ORR voltammograms and (b) Tafel plots for the ORR of different $\mathrm{M}-\mathrm{Fe}-\mathrm{N} / \mathrm{CB}$ catalysts in $0.1 \mathrm{M} \mathrm{H}_{2} \mathrm{SO}_{4}$ at $298 \mathrm{~K}$ by RDE at $1600 \mathrm{rpm}$. Catalyst loading: $1.0 \mathrm{mg} \mathrm{cm}^{-2}$. $I_{\mathrm{ORR}}$ indicates the difference in current density between $\mathrm{O}_{2}$ and $\mathrm{Ar}$ atmospheres.

$I_{\mathrm{ORR}}$ as a function of the potential and the Tafel plots are shown in Figure 6. The ORR onset potentials were tentatively defined as the potential to obtain a clear $I_{\mathrm{ORR}}$ at $-1.5 \mu \mathrm{A} \mathrm{cm} \mathrm{cm}^{-2}$, as indicated by dotted lines in Figure 6b. In these results, all catalysts exhibited high ORR onset potentials around $0.9 \mathrm{~V}_{\mathrm{RHE}}$. The Fe-N/CB catalyst, which was extensively treated in acid media, still exhibited a high ORR performance, even though most of the Fe was dissolved, further supporting the idea that ionic $\mathrm{Fe}$ bound to nitrogen rather than a metallic Fe phase provide the ORR active sites. Among the four catalysts, Ti-Fe-N/CB had the highest ORR onset potential $(\sim 0.94$ $\left.\mathrm{V}_{\mathrm{RHE}}\right)$ and the largest ORR current $\left(-1.83 \mathrm{~mA} \mathrm{~cm}^{-2}\right.$ at $\left.0.60 \mathrm{~V}_{\mathrm{RHE}}\right)$. Our previous research revealed that presence of both $\mathrm{Co}$ and $\mathrm{Ti}$ in Ti-Co-N/CB can create a high density of Co-related active sites and 

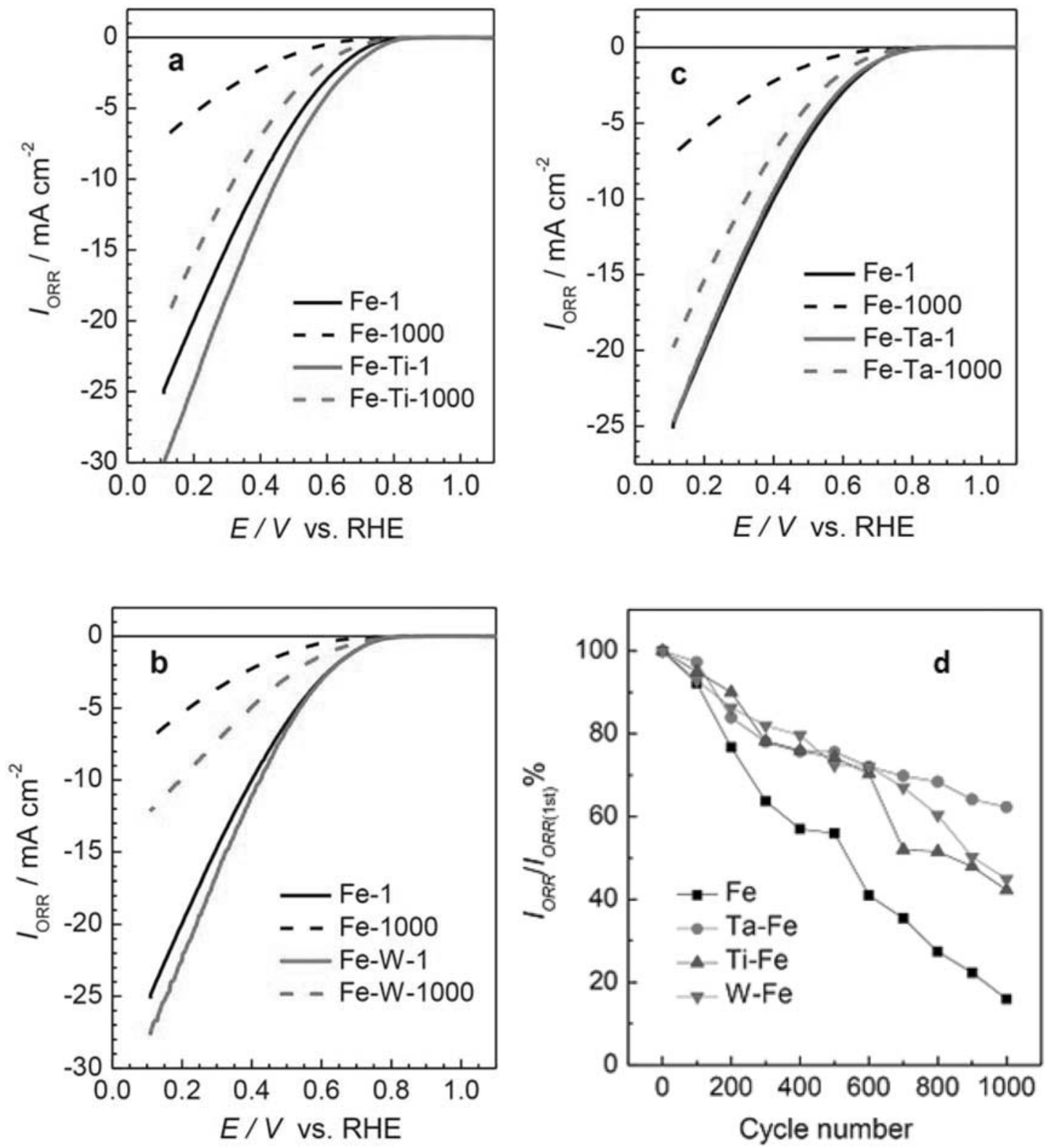

Figure 7. Voltammograms for Fe-N/CB and Ti-Fe-N/CB (a) W-Fe-N/CB (b) or Ta-Fe-N/CB (c) in $0.1 \mathrm{M} \mathrm{H}_{2} \mathrm{SO}_{4}$ at $298 \mathrm{~K}$ before and after durability testing. Solid lines indicate the ORR curves from the first cycle, and dashed lines indicate the ORR curves after 1000 polarization cycles in $0.1 \mathrm{M} \mathrm{H}_{2} \mathrm{SO}_{4}$ between 0.11 and $1.12 \mathrm{~V}_{\mathrm{RHE}}$ at $50 \mathrm{mV} \mathrm{s}{ }^{-1}$ in $\mathrm{Ar}$, with solution replenishment every 100 cycles. $I_{\mathrm{ORR}}$ indicates the difference in current density between $\mathrm{O}_{2}$ and $\mathrm{Ar}$ atmospheres; (d) The ORR current at $0.60 \mathrm{~V}_{\mathrm{RHE}}$ for different M-Fe catalysts relative to the current in the first cycle, as a function of the number of polarization cycles.

highly dispersed Co-Ti species gave better ORR performance than Co species. ${ }^{27}$ In this work, Ti may have been atomically dispersed in the Ti-Fe-N/CB catalyst, which is consistent with the absence of Ti peaks in the XRD results. It is reasonable to consider that this Ti state could not only enhance catalytic activity (higher ORR current and onset potential) through better interaction with the ionic Fe-related active sites, but presenting a higher density of active sites of Fe species by preventing its dissolution (from ICP-MS and UV-Vis results). TaFe-N/CB catalyst had a lower ORR onset potential $\left(\sim 0.90 \mathrm{~V}_{\mathrm{RHE}}\right)$ and ORR current $\left(-1.09 \mathrm{~mA} \mathrm{~cm}^{-2}\right.$ at $\left.0.60 \mathrm{~V}_{\mathrm{RHE}}\right)$ than Ti-Fe-N/CB catalyst. It was reported that Ta phases such as TaON and $\mathrm{Ta}_{3} \mathrm{~N}_{5}$ gave a low ORR current, ${ }^{22}$ and the presence of high-valence state Ta species might not be conducive to presenting a higher density of $\mathrm{Fe}$ ionic active sites because some of the Fe species could be incorporated into the crystalline tantalum phase. In this work, $\mathrm{W}$ did not seem to improve the Fe-related active sites, since W-Fe-N/CB showed an even lower onset potential $\left(\sim 0.87 \mathrm{~V}_{\mathrm{RHE}}\right)$ and ORR current $\left(-1.45 \mathrm{~mA} \mathrm{~cm}{ }^{-2}\right.$ at $\left.0.60 \mathrm{~V}_{\mathrm{RHE}}\right)$ than the other catalysts.

Electrochemical stability tests of different M-Fe-N/CB catalysts and $\mathrm{Fe}-\mathrm{N} / \mathrm{CB}$ catalyst were performed on carbon paper in $0.1 \mathrm{M}$ $\mathrm{H}_{2} \mathrm{SO}_{4}$ at room temperature, with the results shown in Figure 7. It should be emphasized again that the catalyst samples underwent extensive acid treatment, so that the dissolution of unstable metallic species would not influence the catalytic stability of the ORR. It can be seen that all of the catalysts underwent a decrease in ORR current after 1000 polarization cycles, but the degree of current decrease varied. The ORR current at $0.60 \mathrm{~V}_{\mathrm{RHE}}$ for Fe-N/CB decreased from -2.81 $\mathrm{mA} \mathrm{cm}{ }^{-2}$ initially to $-0.44 \mathrm{~mA} \mathrm{~cm}{ }^{-2}$ after 1000 polarization cycles ( $84.4 \%$ loss), proving that simple Fe-N/CB is not a stable catalyst for ORR because the Fe-related active sites degrade in acidic media. ${ }^{7,18}$ Ti-Fe-N/CB started with a higher ORR current of $-4.05 \mathrm{~mA} \mathrm{~cm}^{-2}$ at $0.60 \mathrm{~V}_{\mathrm{RHE}}$, but this decreased to $-1.71 \mathrm{~mA} \mathrm{~cm}^{-2}$ after 1000 cycles (a 
$57.8 \%$ loss). The unstable ORR performance of the Ti-Fe catalyst may have resulted from the instability of the Ti species in acid, as shown in the ICP-MS results, since highly dispersed Ti was supposed to interact with $\mathrm{Fe}$ on ORR active site of the Ti-Fe catalyst. The stability of W$\mathrm{Fe}-\mathrm{N} / \mathrm{CB}$ was also limited, and $I_{O R R}$ decreased from -2.91 to -1.30 $\mathrm{mA} \mathrm{cm}{ }^{-2}\left(55.4 \%\right.$ loss) at $0.60 \mathrm{~V}_{\mathrm{RHE}}$. The $\mathrm{W}$ species did not seem to protect the Fe-related active sites, which may be attributed to the fact that part of the Fe-Phen was dissolved during the acid treatment of the W-Fe sample, as shown in the UV-Vis spectra. The durability of the Ta-Fe-N/CB catalyst is remarkable, and the ORR current at 0.60 $\mathrm{V}_{\mathrm{RHE}}$ decreased from -2.62 to $-1.63 \mathrm{~mA} \mathrm{~cm}^{-2}$ after 1000 cycles of polarization, suffering only a $37.8 \%$ loss. As shown in the plots of Figure $7 \mathrm{~d}$, the deactivation rate of the Ta-Fe catalyst sample was the lowest among the four catalysts, and the Ta-Fe catalyst also produced the highest ORR current at $0.6 \mathrm{~V}_{\mathrm{RHE}}$ after 1000 cycles of the durability test.

The improvements in activity and stability of M-Fe-N/CB catalysts were probably a result of interactions between the $\mathrm{Fe}-\mathrm{N}_{\mathrm{x}}$ active sites and combined metal species. As shown in the previous ICP-MS and UV-Vis analysis, the Fe species are the least susceptible to acid dissolution with the addition of Ta. The acid tolerant Ta-N (or Ta-O) might participate in the formation of $\mathrm{Fe}-\mathrm{N}-\mathrm{C}$ functionality, preserving the active structure as proposed by the previous work. ${ }^{18}$ The electrochemical analysis also confirmed the advantage of enhanced acid tolerance towards electrochemical stability. For the Ti-Fe catalyst, the Ti species should be intrinsically prone to dissolve in acid solution, as demonstrated by the Ti mass loss during acid treatment, causing the low stability of the Ti-Fe-N/CB catalyst. On the other hand, nanosized titanium nitride species have been reported to present a certain activity towards ORR.$^{40}$ In the Ti-Fe catalyst sample, it is quite possible that the highly dispersed Ti composite, which could not be detected by $\mathrm{XRD}$, presented a co-functional phase with the ionic Fe-related active sites, which contributed to the higher ORR activity. The W-Fe catalyst showed little improvement in either activity or stability because the $\mathrm{W}$ failed to interact well with the ionic Fe active sites, as indicate by the XRD results for sharp WC crystalline phase and by the extensive dissolution of the $\mathrm{Fe}$ species. As a result, one approach achieving a more active and stable M-Fe catalyst by the PC-Phen method is the selection of a combined metal to provide a "stable body" to protect ionic $\mathrm{Fe}$ species from loss in acidic media. Such a combined metal should be able to interact with the Fe-related active sites to obtain better ORR performance.

Single-cell test using a Ti-Fe-N/CB cathode.- A power generation test using a single cell containing a Ti-Fe-N/CB cathode was carried out, and the results are shown in Figure 8. Under a pressure of $0.3 \mathrm{MPa}$ (gauge pressure vs. atmosphere) with $\mathrm{H}_{2}$ and $\mathrm{O}_{2}$ flow rates of $500 \mathrm{~cm}^{3}$ $\mathrm{min}^{-1}$ to the anode and cathode, respectively, a high open circuit voltage (OCV) of $0.93 \mathrm{~V}$ and maximum power densities of $480 \mathrm{~mW} \mathrm{~cm}^{-2}$ were attained (Figure 8a). The IR-free power density was estimated to be over $800 \mathrm{~mW} \mathrm{~cm}^{-2}$. This result is among the highest performances reported for PEFCs based on a non-noble metal cathode. The OCVs were 0.86 and $0.88 \mathrm{~V}$ for Ti-Fe- $\mathrm{N}$ and $\mathrm{Fe}-\mathrm{N}$ catalysts, respectively, under a pressure of $0 \mathrm{MPa}$ with $\mathrm{H}_{2}$ and $\mathrm{O}_{2}$ flow rates of $200 \mathrm{~cm}^{3} \mathrm{~min}^{-1}$ to the respective electrodes (Figure $8 \mathrm{~b}$ ). The maximum power densities were 110 and $77 \mathrm{~mW} \mathrm{~cm}{ }^{-2}$ for Ti-Fe-N and Fe-N catalysts, respectively (Figure 8c). This confirms that the presence of Ti in the catalyst formulation does improve the power density, probably by increasing the number of Fe-related active sites. The durability of these two catalysts was examined by continuous potential cycles. At the tenth cycle, the cell performance of Ti-Fe catalyst decreased significantly, and there was little difference from the results from the tenth cycle of the Fe-only catalyst. The Ta-Fe catalyst was also tested for a single cell power generation, but the results were similar and the catalyst showed significant deactivation by potential sweeping cycles. As discussed previously, the presence of foreign elements such as Ti and Ta stabilizes the ORR active sites during acid treatment, but it was obvious that the high-temperature potential sweeps (oxidizing condition) easily decomposed the active structure for the ORR. This study demonstrates
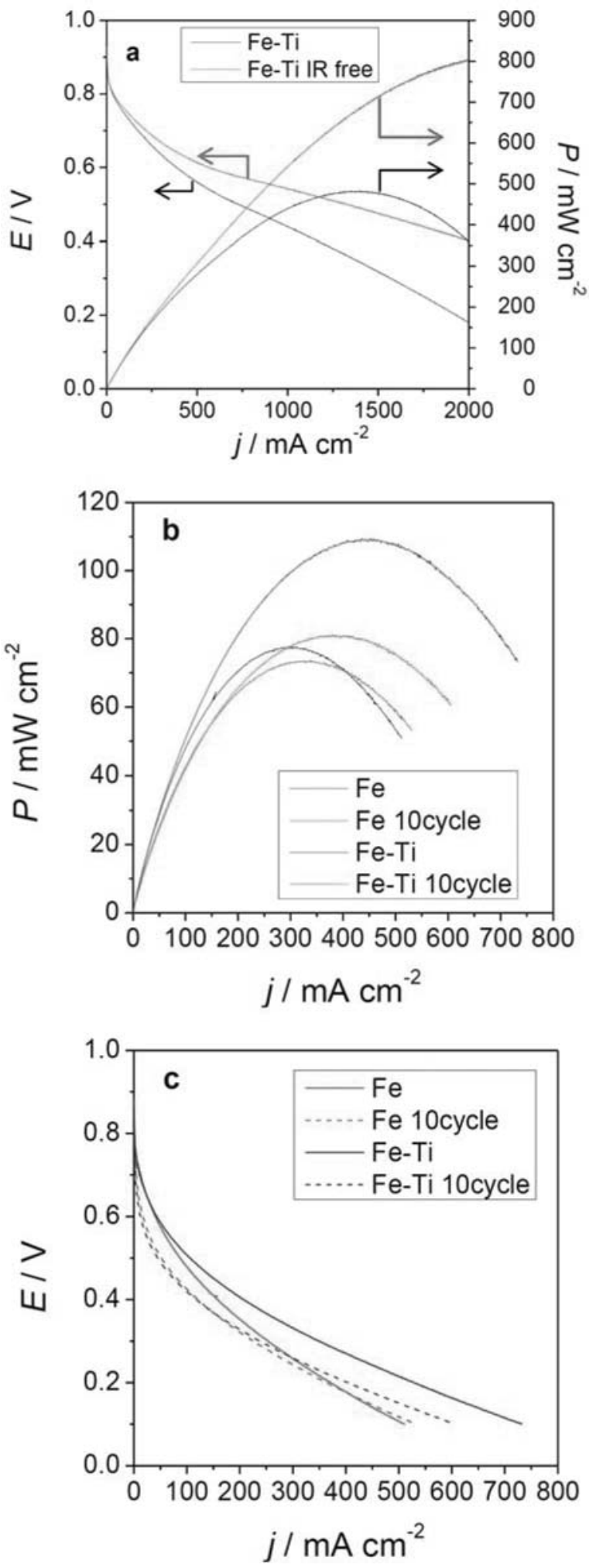

Figure 8. (a) Voltage-current density and power density-current density curves of a single cell using a Ti-Fe-N/CB cathode under 0.2 and $0.3 \mathrm{MPa}$ (gauge pressure) of $\mathrm{H}_{2}$ and $\mathrm{O}_{2}$, respectively, at $500 \mathrm{~cm}^{3} \mathrm{~min}^{-1}$. (b) Power densitycurrent density and (c) voltage-current density curves of a single cell using Ti-Fe-N/CB and $\mathrm{Fe}-\mathrm{N} / \mathrm{CB}$ cathodes under $0 \mathrm{MPa}$ of $\mathrm{H}_{2}$ and $\mathrm{O}_{2}$. In all cases, the temperature of the entire cell was maintained at $363 \mathrm{~K}$ under $\mathrm{H}_{2}$ (anode) and $\mathrm{O}_{2}$ (cathode) flows, and humidification at $363 \mathrm{~K}$ was employed. For further details, see the experimental section. 
the beneficial effects of the addition of transition metals into Fe-based electrocatalysts in terms of an improved dispersion of active sites and a higher tolerance to acid media. However, the stabilization of Fe-based cathode catalysts under actual PEFC operating conditions remains a challenge.

\section{Conclusion}

Catalyst preparation using a PC method with Phen addition significantly improved the ORR performance, apparently reflecting an improved dispersion of the active Fe species. The addition of foreign elements, Ti, Ta, and $\mathrm{W}$, affected the ORR performance in terms of activity and stability. A Ti-Fe-N/CB catalyst exhibited the highest onset potential at $0.94 \mathrm{~V}_{\mathrm{RHE}}$ and the best ORR current among the catalysts investigated. A single cell using a Ti-Fe-N catalyst had a high power density of $480 \mathrm{~mW} \mathrm{~cm}^{-2}$. The improved ORR current from the TiFe-N sample probably resulted from an improved dispersion of active components (possibly the ionic Fe species) due to the presence of highly-dispersed Ti ions. The addition of Ta also improved the acidic and electrochemical stability, which may be attributed to the higher corrosion resistance of the Ta phase and its interaction with the Fe ionic states. This method of adding foreign elements into the catalyst formulation has great potential to establish highly stable performance in the ORR, even though the M-Fe catalysts prepared in this study showed insufficient stability for practical use.

\section{Acknowledgments}

This work was partly supported by the New Energy and Industrial Technology Development Organization (NEDO).

\section{References}

1. L. Carrete, K. A. Freidrich, and U. Stimming, Fuel Cells, 1, 5 (2001).

2. P. J. Ferreira, G. J. la O', Y. Shao-Horn, D. Morgan, R. Makharia, S. Kocha, and H. A. Gasteiger, J. Electrochem. Soc., 152, A2256 (2005).

3. L. Zhang, J. Zhang, D. P. Wilkinson, and H. Wang, J. Power Sources, 156, 171 (2006).

4. R. Jasinski, Nature, 201, 1212 (1964)

5. A. Widelov and R. Larsson, Electrochim. Acta, 37, 187 (1992).

6. U. I. Koslowski, I. Abs-Wurmbach, S. Fiechter, and P. Bogdanoff, J. Phys. Chem. C, 112, 15536 (2008).

7. M. Lefevre and J. P. Dodelet, Electrochim. Acta, 48, 2749 (2003).

8. T. Schilling and M. Bron, Electrochim. Acta, 53, 5379 (2008).
9. G. Faubert, R. Cote, J. P. Dodelet, M. Lefevre, and P. Bertrand, Electrochimi. Acta, 44, 2589 (1999)

10. C. W. B. Bezerra, L. Zhang, K. Lee, H. Liu, J. Zhang, Z. Shi, A. L.B. Marques, E. P. Marques, S. Wu, and J. Zhang, Electrochimi. Acta, 53, 7703 (2008).

11. R. Franke, D. Ohms and K. Wiesener, J. Electroanal. Chem., 260, 63 (1989).

12. M. Lefevre, E. Proietti, F. Jaouen, and J. P. Dodelet, Science, 324, 71 (2009).

13. M. Bron, S. Fiechter, M. Hilgendorff, and P. Bogdanoff, J. Appl. Electrochem., 32, 211 (2002).

14. M. Lefevre and J. P. Dodelet, J. Phys. Chem. B, 106, 8705 (2002).

15. M. Bron, J. Radnik, M. Fieber-Erdmann, P. Bogdanoff, and S. Fiechter, J. Electroanal. Chem., 535, 113 (2002).

16. T. Schilling, A. Okunola1, J. Masa, W. Schuhmann, and M. Bron, Electrochim. Acta, 55, 7597 (2010).

17. C. W. B. Bezerra, L. Zhang, K. Lee, H. Liu, J. Zhang, Z. Shi, A. L. B. Marques, E. P. Marques, H. Wang, and J. Zhang, Electrochimi. Acta, 53, 4937 (2008).

18. H. Schulenburg, S. Stankov, V. Schunemann, J. Radnik, I. Dorbandt, S. Fiechter, P. Bogdanoff, and H. Tributsch, J. Phys. Chem. B, 107, 9034 (2003).

19. J. H. Kim, A. Ishihara, S. Mitsushima, N. Kamiya, and K. Ota, Eletrochimi. Acta, 52, 2492 (2007).

20. R. Ohnishi, Y. Takahashi, A. Takagaki, J. Kubota, and K. Domen, Chem. Lett., 37, 838 (2008).

21. F. Mazza and S. Trassati, J. Electrochem. Soc., 110, 847 (1963).

22. A. Ishihara, K. Lee, S. Doi, S. Mitsushima, N. Kamiya, M. Hara, K. Domen, K. Fukuda, and K. Ota, Electrochem. Solid-State Lett., 8, A201 (2005).

23. G. Liu, H. M. Zhang, M. R. Wang, H. X. Zhong, and J. Chen, J. Power Sources, 172, 503 (2007).

24. A. Takagaki, Y. Takahashi, F. Yin, K. Takanabe, J. Kubota, and K. Domen, J. Electrochem. Soc., 156, B811 (2009).

25. K. Lee, A. Ishihara, S. Mitsushima, N. Kamiya, and K. Ota, Electrochim. Acta, 49, 3479 (2004)

26. F. Yin, K. Takanabe, J. Kubota, and K. Domen, J. Electrochem. Soc., 157, B240 (2010).

27. F. Yin, K. Takanabe, M. Katayama, J. Kubota, and K. Domen, Electrochem. Commun., 12, 1177 (2010).

28. P. Berastegui, H. Mazaki, H. Yasuoka, L. Johansson, S. Eriksson, L. Borjesson, and M. Kall, J. Appl. Phys., 73, 2424 (1993).

29. M. Kakihana and M. Yoshimura, J. Appl. Phys., 71, 3904 (1992).

30. S. K. Guin, R. Chandra, and S. K. Aggarwal, Electrochim. Acta, 55, 8402 (2010).

31. M. Kano, T. Nakagawa, T. A. Yamamoto, and M. Katsura, J. Alloy. Compd., 327, 43 (2001).

32. J. Bainbridge, J. Phys. Chem. Solids, 34, 1579 (1973).

33. W. Lee, J. Lin, and C. Lee, Mater. Chem. Phys., 68, 266 (2001).

34. M. B. Zellner and J. G. Chen, Catal. Today, 99, 299 (2005).

35. X. Wang, W. T. Zheng, H. W. Tian, S. S. Yu, W. Xu, S. H. Meng, X. D. He, J. C. Han, C. Q. Sun, and B. K. Tay, Appl. Surf. Sci., 220, 30 (2003).

36. S. M. Lyth, Y. Nabae, S. Moriya, S. Kuroki, M. Kakimoto, J. Ozaki, and S. Miyata, J. Phys. Chem. C, 11, 20148 (2009).

37. J. Casanovas, J. M. Ricart, J. Rubio, F. Illas, and J. M. Jimenez-Mateos, J. Am. Chem. Soc., 118, 8071 (1996).

38. J. G. Choi, Appl. Catal., A, 184, 189 (1999).

39. M. Stolze, B. Camin, F. Galbert, U. Reinholz, and L. K. Thomas, Thin Solid Films, 409, 254 (2002).

40. J. Chen, K. Takanabe, R. Ohnishi, D. Lu, S. Okada, H. Hatasawa, H. Morioka, M. Antonietti, J. Kubota, and K. Domen, Chem. Commun., 46, 7492. (2010) 